\title{
Pervasive Uncertainty in Second Modernity: an Empirical Test
}

\author{
by Peter Taylor-Gooby \\ University of Kent \\ Sociological Research Online, Volume 10, Issue 4, \\ < http://www.socresonline.org.uk/10/4/taylor-gooby.html> \\ doi:10.5153/sro. 1197
}

Received: 13 Oct 2005 Accepted: 20 Dec 2005 Published: 31 Dec 2005

\begin{abstract}
Recent discussion of social change implies that, for a number of reasons, to do with globalisation, shifts in family life styles and labour markets, more critical attitudes toward the authority of officials and experts and greater awareness of possibilities and options, social life is more strongly affected by a sense of uncertainty. It also implies that uncertainty is pervasive and not specifically linked to fears about specific contingencies. It is associated with an orientation towards self-direction and a rejection of tradition and conformity. This thesis has been widely discussed, but rarely tested using quantitative data. This paper uses data from a recent national survey carried out by the ESRC Social Contexts and Responses to Risk network to show that uncertainty and security concerns are strong, but are in fact linked to traditionalism and conformity rather than to a critical and reflexive awareness. A high value is attached to self-direction, but this is linked to privileged social status rather than attitudes of pervasive social uncertainty. In general the values posited by recent discussion seem to be associated more closely with immediate social position than with the society-wide impact of social change.
\end{abstract}

\section{Keywords: Uncertainty, Traditionalism, Reflexivity, Risk Society, Empirical Test}

\section{Pervasive Social Uncertainty in High or Second Modernity: an empirical test}

1.1 At the abstracted level of the ideal type, the modern stage of societal development is associated with a reliance on technically-advanced industry, producing high rates of relatively secure employment, and a division between working and middle class and between breadwinner husbands and unwaged house-wives in nuclear families. Nation states manage national economies to ensure economic stability. The ideas stemming from the Enlightenment provide the basis for two developments: the rational systems of thought that make modern industry, modern economic management, the conception of science as progressive and the authority of technically-based expertise possible, and the ideal of emancipation that underlies modern democratic politics, modern market systems and modern private life. Industrial nation states became nation states and full employment and a bourgeois form of family life generated expectations about the settled trajectory of the life course for most people (see for example, Jessop, 2002; Beck, 1999; Bauman, 1991).

1.2 A whole array of economic, institutional and cultural shifts mean that this ideal type no longer applies satisfactorily to the developed world. Discussion of risk in recent sociological literature often turns on a particular notion of social change: the evolution of modernity into a new (or second, or high or developed or liquid etc) modernity in which a sense of generalised uncertainty is one of the key themes in how people understand their lives. This paper seeks to test this account using quantitative empirical data. A simplified summary of the shift towards risk society, drawing on Beck, 1992; chapters 1 and 2, Giddens 1994, chapter 2; and Tulloch and Lupton, 2003, chapter 1, would associate this change with some or all of the following:

- At the material level, with the changes in the role of nation states, the international economic system, more rapid communications and broader cultural awareness often summed up as globalisation;

- At the cultural level, with the decline in the importance of traditional normative frameworks described as detraditionalisation;

- At the institutional level, with greater flexibility in family and in working life;

- At the level of subjective consciousness, with greater awareness of these shifts among the population at large (reflexive modernisation): in particular, the perception that the structures and institutions of modernity are increasingly incapable of dealing with the risks and uncertainties that 
people face and, as a result of these shifts, a greater willingness to question received authority, expertise and official understandings (a querulous citizenry);

- At the level of individual motives, with the sense that people face risk and uncertainty more as separate individuals, because the collective structures of modern society have grown weaker and less authoritative. One outcome is a stronger sense of being capable of choosing between the available methods of handling risk and of having no alternative but to take responsibility for such choices (more active trust);

- At the public policy level, with the retreat of the state and greater emphasis on individualism and market co-ordination; and

- At the social scientific level, with a shift towards greater interest in the subjective and cultural processes of risk society and correspondingly less interest in institutional frameworks. Together with the previous point, this is sometimes summed up as the death of the social (Rose, 1996).

1.3 The changes listed above go hand-in-hand. Globalisation sets the context for market liberalisation, greater flexibility and reflexive modernity; detraditionalisation strengthens the role of individual responsibility; the declining authority of received normative frameworks and of social institutional structures directs attention to subjective responses.

$1.4 \mathrm{It}$ is important to be clear that this account of social change does not imply that risks and uncertainties, conceived of as the hazards people face in their day-to-day lives, are any more salient than they were at the height of the modern period, when morbidity and mortality rates were higher, living standards lower and (for much of the 20th century) the dangers to the citizens of the developed world from economic instability and total war much greater. The claim is rather of a cultural shift because the framework of institutions, experiences and assumptions in which people live has shifted, such topics are commonly understood differently. Similarly, the claim that a profound shift, involving the emergence of risk as a central social and governmental category and as the object of policy, has taken place during the lives of the past generation invites question.

1.5 As Rose points out, Ewald and others have demonstrated that risk, understood as manageable through social insurance became a prominent feature of governmental systems during the 19th century (1996, 321 see also Elliott 2002; Dingwall, 1999). A more plausible claim is not so much that the risk management systems of modernity are dissolving, (insurance, social planning, industrial management and marketing strategies clearly continue to flourish) but that subjective orientation to them is shifting and there is a greater awareness of the limits of available policies in tackling risks that seem both pressing but uncertain. The literature emphasizes risks to do with environmental pollution, climate change, dread diseases which science imperfectly understands and the like (see for example, Slovic, 2001). These factors have in common grave consequences, uncertainty as to the likelihood of where they will strike and a generalised (democratic) impact if they do. The suggestion is that a generalised consciousness of uncertainty is emerging alongside the specific concerns which existing risk management systems can competently address (Beck 1999, Giddens 1994, Lash 2000, Bauman, 1991).

1.6 This account of social change raises the question of how the new modernity relates to and interacts with the old. The institutions and structures of traditional modernity clearly co-exist and interpenetrate with those of the new modernity. The insurance industry still exists and provides extensive (and expanding) cover which is used to manage a large number of risks and uncertainties; separation, divorce, cohabitation, remarriage, single parenthood are all on the increase, and new forms of relationship, such as living together apart seem to be emerging, but many people still pursue lives on the assumption that traditional patterns of relationship will endure (Williams 2004); there is a widespread perception that no-one has a job for life, but average job-tenure shows no trend to secular decline, but simply responds to economic cycles, employment contracts continue and training is undertaken in the expectation that an investment in skills will show a return (Green et al., 2002); the nuclear family with bread-winner husband, dependent wife and two children is no longer the norm, but most social care continues to be provided domestically by women kin (Crompton, 1997).

1.7 While a great deal has been written about the possibilities of a shift towards a new modernity, the continuing relationship between the social structures of the new and old modernity has received relatively little attention, especially at an empirical level. This situation is exacerbated by the fact that much of the literature has tended to focus more on detailed accounts of subjective consciousness and perceptions and to pay relatively little attention to the institutional framework of social life. The most developed and influential such study interviews a range of people in different social settings and demonstrates that responses to risk are shaped via such factors as gender, age, occupation, nationality and sexual identity (Tulloch and Lupton, 2003, 132). It shows that the diversity of ways in which people think about and pursue their lives is much greater than that presupposed by a simple risk society framework. However, it does not at this stage take the argument further by attempting to define the range of forms of life that are pursued, 
nor to explore the contribution of factors typically associated with old and new modernity in the lives that are discussed.

1.8 This paper seeks to contribute to this debate by analysing new attitude survey data in relation to hypotheses derived from the risk society thesis to chart out the contours of social consciousness, and to establish the importance of factors relating to the two modernities within it. It distinguishes two accounts of risk: the subjective perceptions of generalised uncertainty distinctively associated with the transition to risk society by theorists, and the specific issues and concerns arising during the life-course which the governmental systems of modernity address. It raises the issue of the role currently played by the social divisions of class, income and education level that were a key aspect of modern society. Much of the debate about a shift towards a new modernity has been carried out in discursive terms, using intensively analysed small sample qualitative data. Analysis using a quantitative approach may usefully contribute to the debate.

\section{Hypotheses}

2.1 The following hypotheses about the patterns of attitudes to a range of everyday life concerns that one would expect to encounter in a random sample of the adult population may be derived from the risk society thesis as stated above.

- 1. An important aspect of peoples current consciousness of their social life is of a pervasive and intractable uncertainty, irrespective of the security of their personal circumstances. This uncertainty is generalised; it is not related to specific issues of concern, but is an overall perception of the condition of a contemporary form of life. We should expect generalised uncertainty to be strongly felt, but that any correlations with particular issues of concern would be weak.

- 2. Consciousness of generalised uncertainty is related to a subjective reflexive modernity, associated with critical thinking about traditional forms of life, rejection of automatic conformity with received principles, and awareness that individuals must take responsibility for their choices. This implies that measures of these general value orientations should display substantial significant correlations, and that generalised uncertainty should relate positively to self-direction, but negatively to traditionalism and conformity.

- 3. Generalised uncertainty is not closely related to the social divisions of interest associated with the socio-demographic roles people occupy in modern society. Modern industry and the politics associated with it makes class position significant; income is associated with class and with consumption power and status; education is significant because it is linked to access to lifechances; sex influences position in a gender division of labour; age is significant due to the stages defined by education, employment, family building, retirement and care during a typical life-course. The specific concerns which occur in the trajectory of peoples lives in modern societies, however, remain related to these social divisions under a second modernity, but now appear alongside the more generalised uncertainty which does not show the same pattern of relationships. We should expect strong and significant relationships between socio-demographic variables and specific concerns but not between these variables and the general value orientations, which are posited as experienced broadly across society.

2.2 To recapitulate, the argument thus far suggests that risk society theories identify a transition from a first to a second modernity in the development of contemporary society. This transition is understood to involve greater uncertainty in peoples consciousness of their own social life, not so much because of the risks faced in work, family life or from the activities of government or business are greater in an objective sense, but because confidence in experts and authorities is waning and because the ordered structures that governed labour markets, traditional families and nation states are under pressure from globalisation. The above hypotheses about uncertainty are derived from this theoretical approach and expressed in a form that can be empirically tested.

\section{Method}

3.1 The data used here to test these hypotheses derive from the National Risk Survey carried out by Andreas Cebulla and colleagues from the National Centre for Social Research and the Centre for Research in Social Policy at Loughborough University as part of the ESRC Social Contexts and Responses to Risk Network. More details of the Network are available on its web pages at <http://www.kent.ac.uk/scarr>. The risk survey completed personal face-to-face interviews with 1395 respondents aged 16 and above from an issued sample of 2000 (69.75\% response rate) in May to June 2004 using a structured questionnaire. The fieldwork was carried out by MORI at 32 sampling points covering England, Wales and Scotland south of the Caledonian canal. The questions asked covered experience of and responses to a range of risks encountered in everyday life, and also included broader questions on trust, uncertainty and social support and socio-demographic classificatory variables. Details of the variables used in the analysis in this paper 
are included in Appendix 1. The survey data will be made available through the ESRC Data Archive (http://www.data-archive.ac.uk/) at the completion of the project.

3.2 Testing the above hypotheses requires information on peoples general value orientations and sense of generalised uncertainty and also on the issues that they recognise as specific concerns, as well as on socio-demographic data. The Schwartz Value Index was used in the survey to examine generalised ideas about individual world-view and value-orientation. This index is theoretically based and has been validated in 42 countries (Schwartz and Sagie, 2000). It seeks to identify and measure the full range of value orientations) and is widely used, for example in the European Social Survey ${ }^{[1]}$.

3.3 The index includes four measures relevant to the shift in consciousness between old and new modernity:

- Uncertainty/Security, which relates to general concerns and uncertainties and is an appropriate measure for the generalised and pervasive uncertainty identified as a distinctive feature of the new modernity by risk society theory ;

- Traditionalism, relating to the extent to which individuals are critically reflexive about received systems of social norms which seek to regulate their behaviour;

- Conformity, concerned with the extent to which they adopt a deferential approach to authority: and

- Self-direction: the extent to which they acknowledge an active role in managing trust and similar issues and see themselves as the responsible author of their own biography. Details are given in Appendix

Raw scores on the various constituent variables of the indices that measure each aspect of valueorientation are averaged and then compared with the average for the index as a whole to establish the distinctive score for the particular aspect of value-orientation. Stronger assent to the item on the index is scored lower, so lower numerical scores indicate stronger commitment to the particular value.

3.4 The survey was extensively piloted. Nine specific concerns covering a wide range of everyday life issues appropriate to experience under both old and new modernity were identified as salient in the lives of respondents:

- having to take on care responsibilities

- losing your job

- your income from work or benefit declining

- becoming a victim of crime

- having a serious accident

- falling seriously ill

- receiving poor customer service, including advice

- rent or mortgage slipping into arrears

- being divorced or separated

The responses are scaled on a four point scale from not at all to extremely worried, so higher scores indicate greater concern.

3.5 In the analysis we wish to contrast the more general value-orientations with the specific concerns to establish how far a pervasive uncertainty and concern for security is linked to detraditionalisation, rejection of conformity and responsibility for self-direction as posited by the risk society approach, rather than to the specific concerns of the life-course listed above. We also wish to examine the extent to which these subjective ideas are patterned by the divisions of interest associated with the various socio-demographic categories or reflect a broader and more generalised uncertainty.

3.6 It should be acknowledged that risk society theories typically analyse a transition between two forms of society, termed here first and second modernity, whereas the data available to this study only refers to one point in time, so that we are unable to assess value change. However, the theories imply that particular relationships between value orientations, specific concerns and social circumstances currently exist. Our data bears on these relationships, and it is this area that we seek to address.

\section{Hypothesis 1: Current value orientations are characterised by pervasive uncertainty}

3.7 Concerns about risks and uncertainty are a prominent feature of value orientations. The measure of orientation to concern about pervasive uncertainty and insecurity is the strongest with a mean of -.42 , followed by self-direction (taking responsibility for ones own life) at -.38 , then conformity at .11 and concern for tradition at .07 . 
3.8 The strength of the various specific concerns varies. Over the sample as a whole, the most prominent concerns are those to do with illness, accident and crime, with the private sphere concerns of separation and divorce and caring responsibilities relatively weak, taking into account relationship and employment status (Table 1)

Table 1. The specific concerns: How worried or concerned are you about any of the following? (\%)

\begin{tabular}{|l|l|l|l|l|l|}
\hline & $\begin{array}{l}\text { Not at } \\
\text { all }\end{array}$ & Somewhat & $\begin{array}{l}\text { Very } \\
\text { much }\end{array}$ & Extremely & Mean \\
\hline Care & 56 & 30 & 10 & 6 & 1.66 \\
\hline Unemployment & 55 & 21 & 12 & 12 & 1.82 \\
\hline Income fall & 42 & 28 & 15 & 15 & 2.02 \\
\hline Crime & 28 & 36 & 20 & 17 & 2.27 \\
\hline Accident & 36 & 30 & 17 & 18 & 2.16 \\
\hline Illness & 30 & 32 & 17 & 21 & 2.30 \\
\hline Poor advice & 40 & 36 & 15 & 9 & 1.94 \\
\hline Arrears & 57 & 16 & 13 & 15 & 1.86 \\
\hline Divorce & 71 & 12 & 7 & 10 & 1.56 \\
\hline N=1395 & & & & & \\
\hline
\end{tabular}

3.9 Correlations between the value-orientations and specific concerns are complex and show a number of relatively weak but significant correlations (Table 2 insignificant correlations are omitted to facilitate interpretation). In all but two cases (uncertainty and concern about falling ill or being a crime victim) they are positive, indicating that the value is associated with a low level of concern. Self-direction appears to limit the extent of apprehension of the contingencies listed. This may be explained in terms of the sense of greater control over ones life associated with such an approach, but it is interesting to note that both tradition and conformity and, in some cases, uncertainty share this relationship.

Table 2. Correlations between value-orientations and specific concerns (Spearman's rho)

\begin{tabular}{|c|c|c|c|c|}
\hline & Uncertainty/Security & Tradition & $\begin{array}{l}\text { Self- } \\
\text { direction }\end{array}$ & Conformity \\
\hline Care & .069 (*k) & $.084(* * k)$ & & $.080(* *)$ \\
\hline Unemployment & $148(* *)$ & $108(* * k)$ & $.092(* *)$ & $184\left({ }^{* * *}\right)$ \\
\hline Income fall & & .086 (***) $^{\circ}$ & & $.096(* *)$ \\
\hline Crime & $-.082(* * *)$ & & .077 (***) $^{*}$ & \\
\hline Accident & & 071 (**) $^{*}$ & 119 (**) $^{* *}$ & $048(*)$ \\
\hline Illness & $-.072(* * *)$ & & .093 (*k*) $^{*}$ & \\
\hline Poor advice & & $.047(*)$ & $.064(* * *)$ & \\
\hline Arrears & & .069 (*k) $^{*}$ & $.051\left(^{*}\right)$ & $124(* * k)$ \\
\hline Divorce & $.054(*)$ & & $.058(*)$ & .071 (k*k) $^{* k}$ \\
\hline
\end{tabular}

* Correlation is significant at the 0.05 level; ${ }^{* * *}$ significant at the 0.01 level (1-tailed).

\section{Hypothesis 2: Pervasive uncertainty, self-direction and other value-orientations}

3.10 There are (as might be expected) strong and significant relationships between the indices. Tradition and conformism are associated with each other, as might be anticipated, but also with greater orientation to security. All three are inversely related to the self-responsibility index (Table 3).

Table 3. The relations between the four value-orientations (Spearman's rho)

\begin{tabular}{|l|c|r|r|}
\hline & Tradition & Self-direction & Conformity \\
\hline Uncertainty/Security & $.133\left(^{* * *}\right)$ & $-.177\left(^{* * *}\right)$ & $.253\left(^{* * *}\right)$ \\
\hline Tradition & & $-.137\left(^{* * *}\right)$ & $.256\left(^{* * *}\right)$ \\
\hline Self-direction & & & $-.238\left(^{* * *}\right)$ \\
\hline
\end{tabular}

* Correlation is significant at the 0.05 level; *** significant at the 0.01 level (1-tailed). 
3.11 So far the analysis does not support the hypotheses derived from a naive approach to risk society. A pervasive sense of uncertainty can be identified and is an important value orientation among those interviewed. However it relates to the specific concerns that are currently highly salient, and is associated directly with traditionalism and conformity. It does not correspond closely to the sense of responsibility for the choices in ones own life-course which might be seen as an aspect of reflexivity in second modernity. A relationship exists, but in the reverse direction: greater uncertainty is associated with lower rather than higher levels of self-direction.

\section{Hypothesis 3: Pervasive uncertainty, social divisions and specific worries}

3.12 We now move on to consider the relationship with the typical social divisions of traditional modern society (Table 4). This shows expected linkages: better educated, more middle-class and younger people and women are oriented towards self-direction, but the relationship is not strong. They are, however, less affected by a pervasive sense of insecurity. The inverse relations to tradition and conformity are substantially stronger and include higher income people. Older people are more strongly conformist and traditional, but also, interestingly, more weakly concerned with self-direction. Relations between social circumstances and the uncertainty/security index are generally rather stronger than elsewhere in the table. This area is particularly the concern of working class, lower income, older and less well-educated people and of women.

Table 4. The value-orientations and socio-demographic variables (Spearman's rho)

\begin{tabular}{|l|r|r|r|r|}
\hline & Uncertainty/Security & Tradition & Self-direction & Conformity \\
\hline Class & $-.140\left(^{* * *}\right)$ & $-.098\left(^{* * *}\right)$ & $.049\left(^{*}\right)$ & -.035 \\
\hline Household income & $.178\left(^{* * *}\right)$ & $.089\left(^{* * *}\right)$ & .001 & $.179\left(^{* * *}\right)$ \\
\hline Gender & $-.129\left(^{* * *}\right)$ & $-.064\left(^{* * *}\right)$ & $-.048\left(^{*}\right)$ & -.032 \\
\hline Age & $-.271\left(^{* * *}\right)$ & $-.311\left(^{* * *}\right)$ & $-.070\left(^{* * *}\right)$ & $-.382\left(^{* *}\right)$ \\
\hline Education level & $.271\left(^{* * *}\right)$ & $.177\left(^{* *}\right)$ & $-.079\left(^{* * *}\right)$ & $.170\left(^{* *}\right)$ \\
\hline
\end{tabular}

* Correlation is significant at the 0.05 level; ${ }^{* * *}$ significant at the 0.01 level (1-tailed).

3.13 The pattern in relation to specific concerns (Table 5) is complex. The more substantial coefficients (greater than 0.15) are in bold and insignificant ones are omitted to facilitate interpretation. Unemployment is particularly a concern of those at the working stage of their life, those with higher incomes, the better educated and relatively younger respondents and also of men. Care responsibilities bear more on middle class and higher educated groups. Rent and mortgage arrears are more an issue for younger and working class groups. The association of concerns about divorce and partnership separation with higher income and younger age also probably reflect life stage. The suggestion that the pattern of worries tends to reflect stage in a typical life-cycle as well social class and income position is reinforced by the widespread associations of the age variable in general the concerns listed here are felt to be more serious among younger groups.

Table 5. The specific concerns and socio-demographic variables (Spearman's rho)

\begin{tabular}{|c|c|c|c|c|c|}
\hline & Class & $\begin{array}{c}\text { Household } \\
\text { income }\end{array}$ & Gender & Age & $\begin{array}{c}\text { Education } \\
\text { level }\end{array}$ \\
\hline Care & $\left.-.1844^{* * *}\right)$ & $112\left(^{* * *}\right)$ & $-.092\left(^{* * *}\right)$ & -139 (**k) & $.228(* * *)$ \\
\hline $\begin{array}{l}\text { Unemployme } \\
\text { nt }\end{array}$ & $-.096\left(^{* * *}\right)$ & $.324\left(^{(* * *)}\right)$ & $-.155\left(^{* * k}\right)$ & $-.432(* * *)$ & $.241\left(^{(* * *)}\right)$ \\
\hline Income fall & $130\left(^{* * *}\right)$ & & & $-.203\left(^{(* * *)}\right)$ & \\
\hline Crime & $.062(*)$ & & $.083\left(^{* * * k}\right)$ & $-.064\left(^{* k *}\right)$ & \\
\hline Accident & $.059\left(^{*}\right)$ & & $112\left(^{(* * *)}\right)$ & $-.194\left(^{* * *}\right)$ & \\
\hline Illness & $087\left(^{*-*}\right)$ & $-.058\left(^{*}\right)$ & $094\left(^{* * *}\right)$ & $-.054\left(^{*}\right)$ & $-.078\left(^{* * *}\right)$ \\
\hline Poor advice & -.023 & $083\left(^{* * *}\right)$ & & $-.114(* * k)$ & 088 (*k) \\
\hline Arrears & $160\left(^{* * *}\right)$ & & & -.269 ( $\left.^{* * *}\right)$ & \\
\hline Divorce & & $.196\left(^{* * *}\right)$ & -.065 (*:*) $^{*}$ & $-.155\left(^{* k *}\right)$ & 067 (***) $^{*}$ \\
\hline
\end{tabular}

* Correlation is significant at the 0.05 level; *** significant at the 0.01 level (1-tailed).

3.14 The relationship between the shift in value orientation posited by the risk society thesis and other values, specific concerns and social factors is complex. In order to understand whether the shift is best 
understood in terms of a general cultural shift or in terms of the concerns of specific social groups, we now move on to multivariate analysis. We argued that the risk society thesis with its stress on generalised uncertainty implies that the links between security orientation and socio-demographic factors should be less prominent than the links with other shifts in consciousness. The claim is that insecurity is experienced broadly as a feature of social life and not concentrated among specific groups. Conversely, the traditional view, that uncertainty is engendered by particular concerns that are typically associated with the vulnerabilities of specific groups and the divisions of interest between them implies that the social factors should be most prominent. Table 6 reports the results of modelling of the value-orientations on other values, specific concerns and socio-demographic factors. Stepwise ordinary least squares regressions are used as a robust technique that enables the scalar level of measurement of the dependent variables to be explored. Standardised coefficients (Beta Weights) are reported where there are significant relationships to enable direct comparisons.

3.15 The regression models predict only between 14 and 19 per cent of the variance in the valueorientations and are mainly of interest because they allow us to compare the impact of the different sociodemographic factors, specific concerns and other values, taken together. The fact that the coefficients between particular value orientations remain stable between the different models gives some confidence in the technique.

Table 6. The value indices, specific concerns and socio-demographic variables: OLS regressions (standardized Beta weights)

\begin{tabular}{|c|c|c|c|c|}
\hline & Uncertainty/Security & Tradition & Self-direction & Conformity \\
\hline \multicolumn{5}{|l|}{ Socio-demographics } \\
\hline \multicolumn{5}{|l|}{ Class } \\
\hline \multicolumn{5}{|l|}{ Household income } \\
\hline Gender & $-.11^{\text {***k }}$ & $-.09^{* * *}$ & $-.13^{* * *}$ & \\
\hline Age & $-.09^{*}$ & $-.29^{*-k}$ & $-.25^{\text {***k }}$ & $-.28^{* k * k}$ \\
\hline Education level & $.21^{* * * *}$ & & & \\
\hline \multicolumn{5}{|l|}{ Specific concerns } \\
\hline \multicolumn{5}{|l|}{ Care } \\
\hline \multicolumn{5}{|l|}{ Unemployment } \\
\hline \multicolumn{5}{|l|}{ Income fall } \\
\hline Crime & $-.10^{* k * k}$ & & & \\
\hline Accident & & & $11^{\text {***k }}$ & \\
\hline \multicolumn{5}{|l|}{ Illness } \\
\hline \multicolumn{5}{|l|}{ Poor advice } \\
\hline \multicolumn{5}{|l|}{ Arrears } \\
\hline \multicolumn{5}{|l|}{ Divorce } \\
\hline \multicolumn{5}{|l|}{ Value orientations } \\
\hline Uncertainty/Security & - & & $-.18^{* * * k}$ & $09^{* * * *}$ \\
\hline Tradition & & - & $-.17^{* * *}$ & $.08^{*}$ \\
\hline Self-direction & $-.18^{* * * k}$ & $-.18^{* k * k}$ & - & $-.28^{* * * *}$ \\
\hline Conformity & $.09^{* * *}$ & $.08^{*}$ & $-.28^{* * * *}$ & - \\
\hline R squared & 0.15 & 0.14 & 0.19 & 0.19 \\
\hline
\end{tabular}

3.16 The value-orientations display the pattern seen earlier: self-direction relates negatively to the other generalized approaches to life. The uncertainty/security index is positively associated with conformity and negatively with self-direction. The specific concerns figure weakly in the models. Those who are most security oriented are most likely to be concerned about crime, while high self-direction is linked to a lower concern about accidents. The demographic variables also retain the former pattern: age is associated with all four value orientations and gender also plays a role, while lower levels of education are linked to higher 
uncertainty.

3.17 All this reinforces the view that the value-orientations of those interviewed, uncertainty and insecurity is linked to a traditionalist social attitude rather than to a more reflexive self-direction, and that this is reflected in linkages with age and life stage.

\section{Implications}

4.1 This analysis indicates a complex pattern of relationships, with some underlying themes:

4.2 A security-orientation certainly exists in the consciousness of many people as do orientations towards tradition, conformity and, on the other hand, self-direction. However, the pattern of relations, in general, is for the first three to link together, contradicting the fourth. Security orientation is perhaps best thought of not so much as the pervasive uncertainty of the risk society thesis, but as a concern about vilnerability in the life-course. This is borne out by the links with specific variables representing typical specific concerns and by the importance of socio-demographic factors indicating lower status and resources in relation to it. Conversely self-direction is not so much to do with the condition of people in a second modernity as with the self-confidence associated with more privileged social position.

4.3 The pattern of specific concerns and their linkages with socio-demographic variables fits the assumption that many of the concerns of everyday life follow the divisions of interest and of advantage established in modern forms of society. Concerns that are loosely related to income affect those with less income or chance of getting it. Other specific concerns, like crime, are more widespread. Finally, value-orientations are not obviously the outcome of specific concerns, but link more to other values and to socio-demographic factors.

4.4 Taken together, these points challenge a simple version of the risk society thesis. Rather they indicate that orientations to risk and uncertainty in our society are very much influenced by specific individual factors rather than the pervasive climate of concern that is implied by the suggestion that a new consciousness of these issues is a key outcome of underlying social changes. Discussion of a transition between a first and a second modernity, towards a risk society is prominent in recent sociology, but has received little extended empirical critique. This paper sets out one method for testing hypotheses derived from the theory using quantitative data. It shows that the value-orientations and social concerns of a first modernity are still important in popular consciousness, despite theoretical assumptions, and that assertions about social transitions may run beyond the evidence.

\section{Appendix: The variables}

\section{Value index}

Here we briefly describe some people. Please read each description tick the box on each line that shows how much each person is or is not like you.

Boxes are labeled: Strong agreement, agreement, neutrality, disagreement and strong disagreement on a five-point scale (male or female pronouns used as appropriate):

- Uncertainty/Security It is important to her that the government ensures her safety against all threats. She wants the state to be strong so it can defend its citizens and It is important to her to live in secure surroundings. She avoids anything that might endanger her safety (average score)

- Tradition Tradition is important to her. She tries to follow the customs handed down by her religion or her family and It is important to him to be humble and modest. He tries not to draw attention to himself. (average score)

- Self-direction It is important to her to make her own decisions about what she does. She likes to be free and not depend on others and Thinking up new ideas and being creative is important to him. He likes to do things in his own original way (average score)

- Conformity It is important to her always to behave properly. She wants to avoid doing anything people would say is wrong and He believes that people should do what they're told. He thinks people should follow rules at all times, even when no-one is watching (average score)

\section{Social Risks}

How worried or concerned are you about any of the following? Scored on a four point scale: not at all worried or concerned; somewhat worried or concerned; very much worried or concerned; extremely worried or concerned. 
- You having to take on care responsibilities in your family Care

- You losing your job Unemployment

- Your income from work or benefit declining Income fall

- You becoming a victim of a crime Crime

- You having a serious accident Accident

- You becoming seriously ill IIIness

- You receiving poor customer service, including advice Service

- Your rent or mortgage slipping into arrears (of 2 months or more) Arrears

- You getting divorced or separated Divorce

\section{Social variables}

Class: A, B, C1, C2, D, E

Income: Annual household income before tax: scale \#0-150,000

Gender: Female $=2$, Male $=1$

Age Scale: $16-17,18-24,25-34,35-44,45-54,55-64,65+$

Education Scale:no qualifications; GCSE/vocational level 2; A-level/HND equivalent; degree; higher degree.

\section{Notes}

${ }^{1}$ Full details of the European Social Survey and a copy of the questionnaire are to be found at: $<$ http://www.europeansocialsurvey.org/>

\section{References}

BAUMAN, Z. (1991) Modernity and Ambivalence,Polity Press: Cambridge.

BECK, U. (1992) Risk Society: towards a new modernity, (tr. M Ritter) Sage: London.

BECK, U. (1999) World Risk Society,Polity Press: Cambridge.

CROMPTON, R. (1997) Women and Work in Modern Britain Oxford University Press: Oxford.

DINGWALL, R. (1999) Risk Society: The Cult of Theory and the Millennium? In: Social Policy and Administration 33, 4, 474-491.

ELLIOTT, A. ( 2002) Becks Sociology of Risk: A Critical Assessment Sociology 36, 2, 293-315.

GIDDENS, A (1994) Beyond Left and Right,Polity Press: Cambridge.

GREEN, F., Felstead, A. and Gallie, D. (2002) Work Skills in Britain 1986-2001, DfES Publications: Nottingham.

JESSOP, B (2002) The Future of the Capitalist State, Polity Press: Cambridge.

LASH, S. (2000) Risk culture Adam, B., Beck, U. and Van Loon, J. (eds.): The Risk Society and Beyond,Sage: London, 47-62.

ROSE, N (1996) Refiguring the territory of government Economy and Society 25, 3, 327-56.

SCHWARTZ, A. and Sagie, G (2000) Value consensus and Importance: a cross-national study, Journal of Cross-Cultural Psychology,31, 4, 465-97.

SLOVIC, P. (2001) The Perception of Risk, Earthscan: London.

TULLOCH, J. and Lupton, D (2003) Risk and Everyday Life, Sage: London.

WILLIAMS, F. (2004) Rethinking Families, Calouste Gulbenkian Foundation 